\title{
A REFUTAÇÃO NO GÊNERO ARTIGO DE OPINIÃO
}

\author{
Refutation in the genre opinion article
}

\author{
Clemilton Lopes Pinheiro*
}

\section{Introdução}

\begin{abstract}
emanalmente, o jornal Folha de São Paulo aponta um assunto polêmico, S na sessão Tendências e Debates, em forma de pergunta para ser respondida com "sim" ou "não", em um artigo de opinião. Por tratarem de um tema polêmico, entendo que os artigos que respondem "não" constituem um ato ilocutório de refutação, através do qual o locutor estatui a falsidade de um estado de fato. Isso envolve dois movimentos: o de negar, em que é declarado o desacordo; e o de argumentar, em que é apresentada a justificativa para a negação.

Ao entender os textos em questão como um ato ilocutório de refutação, presumi que eles poderiam apresentar uma forma de organização peculiar, sobretudo no que diz respeito à articulação dos elementos negativo e argumentativo. É, então, meu objetivo verificar de que forma esse tipo de texto é estruturado e quais as estratégias empregadas para encadear a refutação e a justificação. Os fundamentos teóricos que serviram de base para a análise foram retirados da Semântica Argumentativa.
\end{abstract}

* Universidade Federal de Alagoas 


\section{$O$ ato ilocutório de refutação}

Segundo Ducrot (1977), o ato ilocutório, como todo ato, é uma atividade destinada a transformar a realidade. Essa transformação é de natureza jurídica. Todo ato ilocucional é um ato jurídico na medida em que coloca em jogo uma mudança nas relações legais entre os interlocutores, personagens do diálogo. Por exemplo, o ato ilocutário de perguntar tem como propriedade colocar o interlocutor na obrigação de responder, sujeito, portanto, de uma obrigação.

Para Ducrot, o ato ilocutório tem um caráter intencional, isto é, os direitos e deveres colocados por esse ato são determinados pela existência de uma intenção, ligada a esse próprio ato. No entanto, esse universo de direitos e deveres pode ser recusado pelo destinatário. Essa recusa pode se fazer por meio do ato ilocutório de refutação.

No ato de refutação, ainda segundo Ducrot, ocorre também uma "transformação das relações jurídicas" entre os interlocutores, uma vez que o enunciador é levado a argumentar, a expor as razões de sua refutação e o interlocutor é levado a reagir.

$\mathrm{O}$ ato ilocutório de refutação pode ser caracterizado como um ato representativo reativo constituído de dois componentes: um componente negativo e um componente argumentativo.

Moescher (1982 - apud Brandão, 1998) coloca o ato de refutação na classe dos atos representativos, cujo fim ilocutório é descrever um estado de fato. Como ato representativo, a refutação corresponde a uma proposição em que o locutor estatui a falsidade de um estado de fato.

Ainda segundo Moescher, o ato de refutação se realiza atendendo a quatro condições de emprego: a condição de conteúdo proposicional, a condição de argumentatividade, a condição de sinceridade reflexiva e a condição interacional. A primeira especifica que o conteúdo do ato de refutação é uma proposição (p) que está em uma relação de contradição com uma proposição (q) de um ato de asserção prévio.

A partir da primeira condição se infere que a refutação é ato reativo, isto é, ela se opõe a um ato de asserção prévio. A segunda condição coloca o enunciador da refutação na obrigação de justificar, de dar argumentos em favor da refutação. A terceira condição impõe que o enunciatário acredita que o enunciador crê na falsidade da proposição, objeto da refutação. Finalmente, a quarta condição impõe ao enunciatário a avaliação do ato ilocutório de refutação, de forma positiva, em que o ato é definido como completo; ou negativa, em que a refutação é mal-sucedida. 
O componente negativo do ato refutativo traduz o desacordo do interlocutor. Já o componente argumentativo é o responsável pela busca da adesão. É por meio do instrumental retórico da argumentação que o locutor procura conquistar o seu interlocutor e persuadi-lo. Recorrendo a Perelman, Brandão (1998, p. 89) expõe que "a articulação de um discurso argumentativo supõe sempre dois movimentos: um de desconstrução e outro de construção, visando a uma transformação". Para Brandão, como nunca se argumenta sem o objetivo de modificar de alguma maneira o pensamento ou o julgamento de alguém, a argumentação contém em si um movimento de negação. Não se argumenta sobre evidência ou sobre o que já está firmado. Se isso ocorre "é porque se presume que se possa mudar a opinião do interlocutor; busca-se, então, reforçar uma posição ou sedimentar o julgamento do interlocutor a respeito do problema tratado" (1998, p. 89-90).

Essas considerações acerca do ato ilocutório de refutação me fizeram entender os textos objetos do trabalho (textos que têm como propósito responder negativamente uma questão) como atos de fala refutativos e explicá-los como tal.

\section{Análise da refutação}

Os artigos analisados foram retirados da sessão Tendências e Debates, publicada todos os sábados no jornal Folha de São Paulo. Nessa sessão, são apresentados dois artigos, um com resposta positiva e outro com resposta negativa para uma pergunta que é lançada, geralmente sobre um assunto polêmico, em evidência na mídia, durante a semana.

Escolhi quatro artigos que dizem "não" à pergunta, para verificar de que forma é organizada lingüisticamente a refutação e, dessa forma, fazer algumas generalizações acerca da realização desse fenômeno no gênero textual em questão.

$\mathrm{O}$ artigo $01^{1}$ procura se posicionar negativamente em relação a um projeto, na época aprovado pelo Senado, que prevê a reserva de vagas nas universidades estatais para alunos de escola pública. No início do texto observa-se uma concordância parcial com a idéia do projeto: "O projeto da reserva de vagas aprovado pelo senado tem tudo para receber a aprovação popular. Dá a impressão de resolver uma grave injustiça social". O locutor procura se ligar empaticamente com o seu alocutário, para envolvê-lo nas suas idéias. Nesse momento, anulam-

1 “As universidades estatais devem reservar vagas para alunos de escola pública?" (Folha de São Paulo - 25 set. 1999). Anexo A. 
se as fronteiras entre $\mathrm{L}_{1}$ e $\mathrm{L}_{2}$. Os dois locutores, de uma certa forma, se igualam. No entanto, o movimento de valorização das idéias do alocutário é veementemente refutado. Após parecer concordar parcialmente com $\mathrm{L}_{2}, \mathrm{~L}_{1}$ concretiza a refutação da idéia, através de uma negação frontal: "ele nada resolve e muito menos equilibra; ao contrário, multiplica os problemas e amplia, se não aprofunda, as discriminações".

Após refutar frontalmente a idéia, o locutor passa a expor os argumentos dessa refutação. Apresenta, em seguida, portanto, um primeiro argumento que poderia justificar a refutação, mas o próprio locutor assume que esse argumento não é pertinente para o caso. $\mathrm{O}$ fato de o locutor refutar o próprio argumento constitui uma forte estratégia argumentativa. Se o projeto "fere a autonomia universitária, garantida em Constituição", e isso não serve como argumento que justifique a sua reprovação é porque esse projeto trará para o país conseqüências muito mais sérias: "o agravamento das assimetrias entre o Brasil e os países mais avançados, o aprofundamento da dependência, a cultura reflexa (que nada tem de "cultura") etc. Subdesenvolvimento vai ser pouco".

Ao longo do texto, o locutor vai apresentando outras justificativas para sua refutação. Para concluir, ele apresenta uma forma alternativa de resolver o problema.

$\mathrm{O}$ artigo apresenta, portanto, dois movimentos: um de recusa e outro de justificação dessa recusa. O movimento de recusa se manifestada lingüisticamente por meio de uma força ilocucionária negativa aplicada à asserção, que é retomada por "o projeto" e por "a reserva de vagas". Para imprimir essa negação são usados o operador argumentativo "ao contrário" e as locuções "vai castigar", "demonstra falência", "dá sinais de descrença", as quais são usadas também para encadear os componentes argumentativos.

$\mathrm{O}$ artigo $02^{2}$ se posiciona contra a revogação da lei que pune os crimes hediondos. A organização desse texto segue, embora com pequenas alterações, a mesma organização do texto 01 . O locutor expõe o ponto de vista de $\mathrm{L}_{2}$ para depois refutá-lo frontalmente: “Toda essa argumentação é poesia de pé quebrado". Aliás, deve dizer que, ao expor os argumentos de $\mathrm{L}_{2}, \mathrm{~L}_{1}$, utilizando-se da ironia, já dá pistas de que não concorda com eles, o que antecipa a total refutação.

Segundo Maingueneau (1996, p. 95), numa perspectiva polifônica, na ironia faz-se ouvir uma voz distinta daquela do locutor, ou seja, "uma enunciação polifônica põe em cena uma personagem que enuncia algo de deslocado e do qual o locutor se distancia por seu tom e sua mímica”. Anexo B.

2 “A lei dos crimes hediondos deve ser revogada?" (Folha de São Paulo - 3 out. 1999). 
Passagens como "os que tenham cometido assassinato com requintes de crueldade (...) terão direito a tratamento, suavemente científico"; "nossas penitenciárias precisam de tranqüilidade, não podem transforma-se em notícias todos os dias. Isso perturba nossos governantes" constituem enunciados cuja responsabilidade o locutor não assume, e, mais que isso, enunciados que ele considera absurdos. Assim, no próprio enunciado de $\mathrm{L}_{2}$, há a voz de $\mathrm{L}_{1}$, de uma certa forma, negando-o.

Após afirmar categoricamente sua postura contrária à revogação da lei para crimes hediondos, o locutor passa a expor suas justificativas. Para concluir o texto, ele ratifica a refutação, frontalmente: "Sou contra a revogação"; e joga ainda com um argumento próprio do discurso populista, carregado de conotações axiológicas e de força persuasiva: “Aliás, essa bobagem não dá nem para discutir. Os brasileiros acham a mesma coisa. Por que contrariá-los?"

Nesse texto, há também os movimentos de recusa e justificação. No entanto não é a asserção que é refutada, mas o argumento, como revela o elemento retomador "Toda essa argumentação." A negação é manifestada pelas locuções "poesia de pé quebrado", "Sou contra".

Há ainda, nesse texto, um movimento de encadeamento refutação/ justificação que não existe nos demais. As formas de encadeamento refutação/ justificação expressas por "urgente, sim" e "devemos, isso sim" apresentam uma oposição mais forte, em que é reiterado um valor de negação e afirmação absoluta e categórica.

$\mathrm{O}$ artigo $03^{3}$ se posiciona contra o fato de a cobrança de pedágio urbano ser uma boa alternativa para o trânsito. Essa questão levantou muita polêmica, na época em que foi proposta pela prefeitura de São Paulo.

A estrutura desse texto também segue o padrão dos anteriores: faz-se uma asserção para ser refutada. O locutor afirma, baseado em um princípio constitucional, que a cobrança de pedágio é permitida. Mas é também com base no mesmo princípio que ele apresenta a sua refutação: "No entanto, a exceção prevista para a cobrança de pedágio somente se aplica às vias interestaduais e intermunicipais, pois o referido artigo (artigo 150, V) só permite a criação de tributos com essa natureza". O locutor então se posiciona contra a cobrança de pedágio nas vias de circulação das cidades por ser essa cobrança inconstitucional.

Além dessa inconstitucionalidade do projeto, o locutor apresenta outra que ratifica sua refutação: "o dispositivo constitucional em comento também estabelece que a cobrança de pedágio serve para financiar a manutenção das

3 “A cobrança de pedágio urbano é uma boa alternativa para o trânsito?" (Folha de São Paulo - 9 out. 1999). Anexo C. 
rodovias. Esse ponto traz à tona outra inconstitucionalidade do projeto proposto em São Paulo, pois a regra que se cria é o financiamento também da própria obra". A partir daí são expostas as justificativas da refutação, a maioria delas, aliás, baseadas em princípios constitucionais.

Nesse texto, o movimento de recusa não se manifesta através de um ato ilocucionário de negação. A asserção é encadeada à refutação através do operador argumentativo "no entanto". Segundo Koch (1995, p. 35), esse operador serve para contrapor argumentos orientados para conclusões contrárias. "O locutor introduz em seu discurso um argumento possível para uma conclusão R; logo em seguida, opõe-lhe um argumento decisivo para a conclusão contrária não-R".

O artigo $04^{4}$ refuta a idéia de que a Constituição deve ser mudada para permitir a contribuição dos inativos. Sabe-se que, no Brasil, após a aposentadoria, o trabalhador não precisa mais contribuir com a Previdência Social. Como forma de resolver parte dos muitos problemas por que passa a Previdência Social brasileira, foi proposta a cobrança de contribuição dos servidores públicos aposentados e pensionistas. E como fere um preceito constitucional, essa proposta provocou grande polêmica.

A estrutura inicial desse texto é pouco diferente da dos anteriores. Assim como nos textos anteriores, primeiro se apresenta a voz de outro locutor $\left(\mathrm{L}_{2}\right)$, só que, nesse caso, essa voz é usada para, já de início, refutar a idéia. Na verdade, isso já constitui uma estratégia argumetativa manipulada pelo locutor, basta ver que, ao citar as palavras do presidente do Supremo Tribunal Federal, ele recorre a um argumento de autoridade: "Tomo emprestadas as palavras do presidente do Supremo Tribunal Federal, ministro Carlos Velloso, ditas dois dias após a Corte Suprema, por unanimidade, proibir a contribuição providenciária (...)".

A seguir é feita a asserção a respeito da mudança na Constituição para permitir a cobrança de contribuição dos inativos, para ser imediatamente refutada: "É absurdo propor mudanças na Constituição para uma medida inócua, pois é óbvio que a causa fundamental do déficit está nos encargos financeiros da união".

O texto segue com a refutação dos argumentos utilizados pelo governo para justificar a mudança na Constituição: "É surpreendente constatar que o discurso oficial ainda seja aceito, pois transforma em causa o que é efeito", "Há outras verdades escondidas no jogo de palavras do governo".

4 “A constituição deve ser mudada para permitir a contribuição dos inativos?" (Folha de São Paulo - 23 out. 1999). Anexo D. 
O movimento de recusa é manifestado lingüisticamente pelo ato ilocucionário de negação, impresso por expressões como "é absurdo", "é surpreendente aceitar". Alguns dos componentes negativos são encadeados ao componente argumentativo através do conector "pois".

De forma geral, a análise dos quatro artigos revela um perfeito paralelismo estrutural no que diz respeito à articulação asserção/refutação: a cada ato de asserção corresponde um ato de refutação. É como se houvesse um diálogo, de duas vozes, uma que afirma $\left(\mathrm{L}_{2}\right)$ e outra que refuta $\left(\mathrm{L}_{1}\right)$. No entanto, o discurso de $\mathrm{L}_{2}$ só existe no interior do discurso de $\mathrm{L}_{1}$, em que é retomado de forma relatada para ser refutado.

Acerca disso, Brandão destaca o seguinte:

Todo ato de refutação apresenta um duplo movimento: reconhecimento/manutenção do discurso do outro para depois recusá-lo. Esse reconhecimento/manutenção pode representar uma maior ou menor adesão ao discurso do outro, comportando respectivamente uma recusa mais fraca ou mais forte. (BRANDÃO, 1998, p. 111)

A recusa é sempre muito forte, em todos os artigos. Como a adesão é mínima, e, em alguns casos, praticamente nula, há um afrontamento radical de $\mathrm{L}_{1}$ diante de $\mathrm{L}_{2}$. Isso é percebido pela clara desqualificação do discurso de $\mathrm{L}_{2}$, como se pode ver em diversas passagens dos textos: "tamanha estreiteza" (texto 01), "poesia de pé quebrado" (texto 02), "argumento insustentável" (texto 04).

Entendo ainda que a estratégia de refutar e apresentar argumentos, comum a todos os textos, é mais uma forma, bastante eficaz, de recusa do discurso do outro. Tomo esse raciocínio de Brandão (1998, p. 90), que, considerando o fato de a refutação ser um ato ilocutório composto por um componente negativo e outro argumentativo, questiona se isso não constituiria um duplo movimento de recusa do outro.

Uma primeira recusa contida explicitamente no ato formal de negar e uma segunda recusa contida implicitamente na colocação dos argumentos e contra-argumentos que, numa correlação de forças, devem prevalecer sobre os do interlocutor, coagindo-o a renunciar a sua posição? 
O movimento de recusa é quase categoricamente manifestado por meio de uma força ilocucionária de negação, aplicada às asserções e impressas por marcadores potenciais de refutação. Também, no geral, não há elementos específicos, operadores ou conectores argumentativos, realizando o encadeamento entre os componentes negativo e argumentativo.

\section{Conclusão}

Neste trabalho, apliquei alguns pressupostos da Semântica Argumentativa, nos termos da que foi desenvolvida por Oswald Ducrot, a um tipo de gênero textual: artigos de opinião publicados na sessão Tendências e Debates, do jornal Folha de São Paulo, os quais têm como propósito refutar uma idéia.

Dada a especificidade que apresentam esses artigos de refutar uma idéia, parti do pressuposto de que poderiam apresentar uma organização peculiar. Tracei, então, como objetivo do trabalho, verificar, por meio de amostragem, a estrutura dos textos, com o propósito de depreender alguns traços gerais que caracterizam o artigo de opinião de força refutativa.

A refutação se carateriza como um ato representativo e reativo, composto por dois componentes: um negativo e um argumentativo. É um ato representativo porque corresponde a uma proposição em que o locutor estatui a falsidade de um estado de fato, e reativo, porque se opõe a um ato de asserção prévio. $\mathrm{O}$ componente negativo traduz o desacordo do locutor com o seu interlocutor; o argumentativo garante a busca de adesão.

Todos os artigos analisados se opõem claramente a um ato de asserção prévio, ou seja, a resposta positiva que poderia ser dada à pergunta lançada pelo jornal. Assim, o texto que responde, por exemplo, a pergunta "A cobrança de pedágio urbano é uma boa alternativa para o trânsito?" toma como prévia a asserção "A cobrança de pedágio urbano é uma boa alternativa para o trânsito" e reage a ela, estatuindo sua falsidade. Primeiro é colocada a asserção para depois ser refutada. Nesse movimento, percebe-se a presença da voz de dois locutores: $\mathrm{L}_{2}$, autor da asserção, e $\mathrm{L}_{1}$, autor da refutação. A voz de $\mathrm{L}_{2}$ só existe no interior do discurso de $\mathrm{L}_{1}$, que a retoma para negá-la.

$\mathrm{O}$ movimento de recusa se manifesta lingüisticamente por meio de um ato ilocutário de negação aplicada às asserções e impressas por marcadores de refutação, como operadores argumentativos. Após esse movimento de recusa 
vem o de justificação. Esses dois componentes nem sempre trazem marcas explícitas de encadeamento.

Como fecho do trabalho, destaco o fato de que a análise aqui empreendida mostrou como os princípios teóricos da Semântica Argumentativa possibilitam o surgimento de perspectivas de análises textuais muito ricas, que, inclusive, podem ser aplicadas ao ensino da língua escrita.

\title{
RESUMO
}

O objetivo deste trabalho é verificar, por meio de amostragem, alguns aspectos da estrutura de artigos de opinião de força refutativa, com o propósito de depreender alguns traços gerais que caracterizam a refutação nesse tipo de gênero textual.

Palavras-chave: argumentação, gênero textual, refutação.

\begin{abstract}
This work aims at examining, through sampling, some structural aspects of opinion articles of refutable power, while attempting to define some general lines that characterize refutation in that type of textual gender

Key-words: argumentation, textual gender, refutation.
\end{abstract}

\section{REFERÊNCIAS}

BRANDÃO, H. N. Subjetividade, argumentação, polifonia: a propaganda da Petrobrás. São Paulo: Unesp, 1998.

DUCROT, O. Argumentação e topoi argumentativos. In: GUIMARÃES, E. (Org.). História e sentido na linguagem. Campinas: Pontes, 1989.

. O dizer e o dito. Campinas: Pontes, 1987.

Principios de semântica lingüistica: dizer e não dizer. São Paulo: Cultrix, 1977.

KOCH, I. V. A inter-ação pela linguagem. São Paulo: Contexto, 1995.

MAINGUENEAU, D. Elementos de lingüística para o texto literário. São Paulo: Martins Fontes, 1996. 


\section{ANEXOS}

\section{$\operatorname{AnexoA}$}

As universidades estatais devem reservar vagas para alunos de escolas públicas?

\section{NÃO. A ilusão das cotas.}

O projeto da reserva de vagas aprovado pelo Senado tem tudo para receber a aprovação popular. Dá a impressão de resolver uma grave injustiça social e parece mesmo que equilibra ricos e pobres nas universidades públicas, que vêm sendo descritas ultimamente como um universo de privilegiados. Entretanto ele nada resolve e muito menos equilibra; ao contrário, multiplica os problemas e amplia, se não aprofunda, as discriminações. Poderia, neste curto espaço, afirmar que o projeto fere a autonomia universitária, garantida em Constituição. Pouco adiantaria esse argumento num país que deixa a educação superior transformar-se em negócio, e negócio movido pelo ânimo exclusivo do lucro. A visão estreita do que seja ensino superior público costuma abolir as diferenças, como se a homogeneização das universidades, desde o acesso dos estudantes, as fortalecesse como provedoras do mercado. Qualquer pessoa medianamente informada sabe qual vai ser, em futuro muito próximo, o custo de tamanha estreiteza: o agravamento das assimetrias entre o Brasil e os países mais avançados, o aprofundamento da dependência, a cultura reflexa (que nada tem de "cultura") etc. Subdesenvolvimento vai ser pouco. O projeto, se consolidado, vai castigar todas as famílias que, a contragosto e, na maior parte, com sacrifícios, foram compelidas a matricular os filhos em escolas privadas de ensino fundamental e médio, por acreditar que, nestas, a instrução de boa qualidade se alia a processos formativos integrais e totalizantes, desenvolvidos em ambiente saudável e seguro. Os perfis socioeconômicos dos matriculados em universidades públicas e disponíveis nestas mostram com clareza essa opção forçada que os pais fizeram por saberem ou sentirem que nessas universidades o ensino será de melhor qualidade, porque nelas se cultiva ainda a idéia de que devem ser o lugar dos melhores alunos. Infelizmente, o projeto demonstra, por vias travessas, a falência do ensino público fundamental e médio; mais ainda, dá 
sinais de descrença em todos os projetos do governo que formulam a possibilidade de recuperação desses níveis de ensino. Propondo-se a reserva de vagas, confirma-se o desconhecimento que muitos políticos têm das universidades públicas. Imaginam eles que as universidades são fábricas de profissionais demandados pelo mercado. Esquecem-se das funções que as universidades públicas desempenham com diferentes grau e natureza, por razões históricas e geográficas; esquecem-se principalmente, no quadro dessas funções, daquela que as centraliza no Brasil: a pesquisa científica e tecnológica. Como abrigar alunos fora das exigências de qualidade? Fazendo isso, não se estará praticando o inverso do pretendido pelo projeto, ou seja, não se estará aumentando o índice (já elevado) de evasão de alunos? Que tal um projeto de investimento maciço e necessariamente prioritário na qualidade do ensino público fundamental e médio? Se isso ocorresse - e estou convicto de que as universidades públicas se empenhariam na sua concretização -, em pouco tempo teríamos estudantes egressos de escolas públicas competindo em pé de igualdade com os das escolas privadas nos processos seletivos para o ensino superior; e, depois de mais algum tempo, a desvantagem seria do outro lado, a começar do fato de que poucas escolas privadas subsistiriam. Que famílias iriam procurá-las se o ensino público gratuito fosse de boa ou de melhor qualidade?

Antonio Manoel dos Santos Silva, 57, professor de literatura brasileira, é reitor da Universidade Estadual Paulista (Unesp) e presidente do Conselho de Reitores das Universidades Estaduais Paulistas (Cruesp).

\section{Anexo B}

\section{A lei dos Crimes Hediondos deve ser revogada? NÃO. Revogar a lei sem revogar os crimes?}

Está crescendo a campanha pela revogação da Lei dos Crimes Hediondos, mas só da lei, não dos crimes. A proposta é punir com mais suavidade os delinqüentes de maior periculosidade. Devemos tratá-los com carinho, humanidade, pedagogia, na esperança de que se recuperem para o convívio social e, um dia, ou uma noite, venham a ser úteis para a sociedade, ou mais delicados para com a próxima vítima, posto que reeducados. Tocados pelo 
entendimento de que a pena privativa de liberdade está ultrapassada, alguns respeitáveis cientistas do direito se batem pelas sanções alternativas, prestação de serviços para a comunidade, por exemplo. Assim, os que tenham cometido assassinato com requintes de crueldade, os estupradores, traficantes de drogas, seqüestradores por extorsão e formadores de quadrilha terão direito a tratamento digno, suavemente científico, em condições que não concederam às vítimas. Gostaria que a tese fosse submetida a plebiscito e o povo desse a última palavra. Ouso prever o resultado: $90 \%$ diria não. Há, ainda, o argumento da moda: o condenado sem esperanças de progredir no cumprimento da pena, ou de obter liberdade condicional, ou alguns privilégios pelo bom comportamento, será sempre um elemento perturbador do ambiente penitenciário. Fomentará rebeliões, quebra-quebras, fugas, queimará colchões, fará reféns dos carcereiros. E nossas penitenciárias precisam de tranqüilidade, não podem transformar-se em notícias todos os dias. Isso perturba os governantes. Toda essa argumentação é poesia de pé quebrado. Há um percentual de delinqüentes que jamais se recuperam, mesmo se submetidos aos mais avançados métodos de "reeducação". Urgente, sim, será a revisão do sistema carcerário brasileiro. O recluso, claro, não deve ter o tratamento que dispensou à vítima. A sanção legal não é vingança. Mas deve ser severa, se possível contemporânea à prática do crime, e, nos crimes hediondos, longa, para afastar o meliante do convívio social, que feriu e ferirá novamente se voltar a pretexto de serviços alternativos. Basta verificar quantos bandidos cometem repulsivas atrocidades contra as pessoas e, quando presos, fica-se sabendo que estavam anteriormente condenados e que, nessa condição, foram postos em liberdade condicional ou fugiram, mas voltaram a delinquir e com mais violência. Citam-se estatísticas de outras partes do mundo, mas não se explica a tragédia que o povo brasileiro está vivendo a cada esquina, em cada ônibus, na saída de cada escola, na porta das fábricas, nas estradas. Ninguém sabe se volta vivo para casa. Se o filho volta. Se a filha volta. Além dessa ameaça constante, contra a própria vida de cada um, ainda passamos a vergonha de ver bandidos com cargos eletivos, ostentando para o grande e respeitável público do crime as compensações dos seus delitos, alguns de completa barbaridade, como o assassinato de pessoas mediante o uso de serra elétrica para cortar braços e pernas enquanto vivas. Aí está um bom exemplo de prestação de serviços alternativos. Vamos revogar a lei sem revogar a serra elétrica, que em árvores já consuma crimes, quanto mais em gente! Devemos, isso sim, tornar a lei mais rigorosa. Sou contra a pena de morte, pela possibilidade do erro judiciário. Mas devemos adotar a prisão perpétua para determinado tipo de crimes cruéis. E não relaxar no cumprimento da pena. É preciso separar esse tipo de criminoso dos 
outros, de potencialidade menos lesiva, a fim de que as prisões não se tornem escolas universitárias de delitos. É preciso que se construa a penitenciária federal no centro da região amazônica e que, alterando a lei de execuções penais, para lá sejam enviados os perigosos, que cumprirão suas penas gratificados pela floresta, pela natureza, pelas flores, pela agricultura, pela pescaria, mas fiquem por lá até o último dia da condenação que lhe foi imposta pela Justiça. Os alemães (democráticos) costumam chamar de "Umwelt" o mundo do crime, que entendem incorrigível, posto que há o "Umwelt" irrecuperável. Todos sabem disso. Por que revogar a lei, a única no Brasil, que trata com maior rigor o bandido cruel? Se falhas lhe possam ser atribuídas, que se lhes corrijam. Creio, porém, que as falhas, nessa lei, têm sido sua pouca e inadequada aplicação. Bem aplicada e aplicada sempre, com rigor, vai intimidar parte da bandidagem. Sou contra a revogação. Aliás, essa bobagem não dá nem para discutir. Os brasileiros acham a mesma coisa. Por que contrariá-los?

José Saulo Pereira Ramos, 70, é advogado em São Paulo. Foi consultorgeral da República e ministro da Justiça (governo Sarney).

\section{Anexo C}

\section{A cobrança de pedágio urbano é uma boa alternativa para o trânsito? NÃO. Rua, a maior expressão do bem público.}

A Constituição, ao disciplinar as limitações ao poder de tributar, em seu artigo $150, \mathrm{~V}$, proíbe a instituição de tributos interestaduais ou intermunicipais que limitem o tráfego de pessoas ou bens, excetuando a cobrança do pedágio. Tal dispositivo traz ínsita a proibição constitucional às limitações à liberdade de locomoção, como forma de reforçar o direito fundamental de ir e vir. No entanto, a exceção prevista para a cobrança de pedágio somente se aplica às vias interestaduais e intermunicipais, pois o referido artigo só permite a criação dos tributos com essa natureza. Em outro dizer, o permissivo constitucional só se refere à cobrança de pedágio em vias que extrapolem o limite municipal, aplicandose a regra da não-tributação da locomoção no interior da urbe. Além disso, o dispositivo constitucional em comento também estabelece que a cobrança de pedágio serve para financiar a manutenção das rodovias. Esse ponto traz à tona 
outra inconstitucionalidade do projeto proposto em São Paulo, pois a regra que se cria é o financiamento também da própria obra, o que acaba por onerar por demais o cidadão usuário, em contrariedade ao texto constitucional. A diferenciação de regras para as vias intermunicipais e intramunicipais se deve ao fato de que o município é o centro da vida ativa (ou de atividades) das pessoas. A rua é a maior expressão que se tem de um bem público e não se pode privar ou restringir o acesso a ela, sob pena de prejudicar drasticamente a liberdade e a vida civil dos munícipes. Ora, num país em que as pessoas mal têm condições de arcar com os custos do transporte popular (ou público), instituir pedágio para circular dentro da cidade é por total descabido. O pedágio, aliás, como tributo mais antigo, é cobrado desde a Idade Média na travessia de cidades, jamais dentro delas. A instituição do pedágio urbano num país pobre tem conseqüências catastróficas. As pessoas não podem ser alijadas da liberdade de se locomover em sua cidade, pois tal locomoção representa a execução das suas necessidades mais básicas. E foi atento a isso que o constituinte apenas previu a instituição de pedágios em vias intermunicipais e interestaduais.Vê-se que o município de São Paulo, após seguidas administrações que levaram sua saúde financeira a estado terminal, agora busca financiar a construção de ruas por meio da iniciativa privada. Até aí, tudo bem. No entanto, a forma proposta para tapar o rombo orçamentário só vai servir aos mais abastados, que poderão pagar mais um tributo para poder circular com seus automóveis pela cidade. Isto é, além de pagar IPI, ICMS, imposto sobre combustíveis, IPVA e licenciamento, terão de pagar mais um tributo para poder circular nas vias urbanas. Tal tributação conota verdadeiro confisco, esbarrando, então, em outra limitação ao poder de tributar, expressa no artigo 150, IV, da Constituição Federal. Além disso, cria-se uma forma odiosa de discriminação social, pois o rico poderá circular livremente pela via "pública" de qualidade, a qual será mantida com a arrecadação do pedágio e terá um trânsito mais livre, enquanto o mais pobre terá de ficar parado na via pública, que tem a qualidade que bem conhecemos. É o poder aquisitivo diferenciando as pessoas, diante de um bem público e demasiadamente necessário para que as pessoas gozem da forma mais rudimentar de liberdade, que é o direito de locomoção. Trata-se de solucionar o problema somente para as classes mais abastadas, relegando ao resto o caos hoje instaurado. Tal fato acaba por contrariar outro dispositivo constitucional, que estabelece como objetivo da República Federativa do Brasil a erradicação da marginalização e a redução das desigualdades sociais, bem como a construção de uma sociedade justa e livre. A cobrança do pedágio não representará melhoria nenhuma para os demais cidadãos (sejam eles usuários de transporte privado ou público), uma vez que o 
projeto de lei não prevê nenhuma forma de retorno das verbas arrecadadas ao município, ficando os efeitos de tal dinheiro limitados aos usuários das vias taxadas e à empreiteira que a administrar. O peso do erro acumulado através dos anos, que deixou esse patrimônio negativo, tem que ser compartilhado com todos, ricos e pobres.

Celso Ribeiro Bastos, 61, advogado constitucionalista, é professor de pós-graduação em direito constitucional e direito das relações econômicas internacionais da PUC (Pontifícia Universidade Católica) de São Paulo e diretorgeral do IBDC (Instituto Brasileiro de Direito Constitucional). E-mail: ibdc@aldeiaglobal.com.br

\section{Anexo D}

\section{A Constituição deve ser mudada para permitir a contribuição de inativos? \\ NÃO. Imprevidentes e agiotas.}

“Os projetos governamentais devem ajustar-se à Constituição, e não esta àqueles." Tomo emprestadas as palavras do presidente do Supremo Tribunal Federal, ministro Carlos Velloso, ditas dois dias após a Corte Suprema, por unanimidade, proibir a contribuição previdenciária para servidores públicos aposentados e pensionistas, dado seu caráter confiscatório e ilícito.Acostumado a fazer o que bem entende, com o apoio da maioria no Congresso, FHC prefere ignorar os limites impostos pelo Estado de Direito. Mais uma vez decide mudar a Constituição para moldá-la a seus propósitos e com o argumento insustentável de que sem a taxação dos aposentados não se reduz o déficit público. É absurdo propor mudanças na Constituição para uma medida inócua, pois é óbvio que a causa fundamental do déficit está nos encargos financeiros da União, representados pelos juros e pela rolagem das dívidas interna e externa. Uma comparação entre o primeiro semestre do Orçamento de 1999 com o mesmo período de 1998 revela que o esforço de arrecadação ao qual a sociedade brasileira vem sendo submetida está sendo consumido com o pagamento de juros, enquanto a correlação entre despesas de pessoal e receitas correntes mantém- 
se inferior a $25 \%$. No primeiro semestre de 1999 os gastos com pessoal cresceram $\mathrm{R} \$ 1,8$ bilhão em relação a 1998, mas os gastos com juros aumentaram em $\mathrm{R} \$ 10$ bilhões. Aliás, pela primeira vez em nossa história, a conta de juros e serviços da dúvida ultrapassou a folha de pessoal da União, somando ativos e inativos civis e militares. Na comparação com o Orçamento de 1995, o desequilíbrio é ainda mais gritante. As receitas correntes, nos primeiros semestres, cresceram R $\$ 13,5$ bilhões de 95 para 99, mas as despesas com juros aumentaram em R $\$ 20$ bilhões, ou seja, o serviço da dívida, sem contar as amortizações, sorveu todo o crescimento da receita e mais R $\$ 6,5$ bilhões. Em 95 as despesas com juros representavam $7,07 \%$ das receitas correntes. No primeiro semestre de 1999 , saltaram para $25,89 \%$. É surpreendente constatar que o discurso oficial ainda seja aceito, pois transforma em causa o que é efeito. São as elevadas e abusivas taxas de juros - pedra angular do falido Plano Real - que causam o déficit, e não a folha de pagamento de servidores. Além do mais, o governo federal mente ao afirmar que a contribuição dos servidores aposentados e pensionistas ajudaria a equilibrar as contas. Tomemos como exemplo os funcionários da área de educação. O dinheiro para pagamento de salários e benefícios nem sequer sai do Tesouro Nacional. Por uma manobra contábil do governo Collor, eles foram incluídos no orçamento do Ministério da Educação, portanto o desconto previdenciário não passaria de uma expropriação salarial pura e simples, uma vez que nenhum centavo do que fosse arrecadado retornaria ao MEC. Há outras verdades escondidas no jogo de palavras do governo. A imprevidência histórica com que vem sendo tratada a seguridade social no Brasil é uma delas. Omite-se, por exemplo, que, durante décadas, a União apropriou-se dos resultados positivos da Previdência, mesmo sabendo que estava comprometendo o futuro. Recursos que hoje fazem falta foram desviados para financiar grandes obras, como a construção de Brasília. Além de tirar do caixa da Previdência o que não podia, o governo deixou de depositar o que devia. Hoje, a seguridade social deveria ter uma reserva técnica para cobrir as futuras aposentadorias e pensões composta pela contribuição de empregados e empregadores. Os servidores públicos sempre deram a sua parte, que variou de $6 \%$ a $12 \%$ dos salários, mas o empregador, a União, parou de depositar os $8 \%$ do FGTS e se desobrigou de contribuir para o INSS com $20 \%$ do total da remuneração dos servidores. O que vemos é uma inversão de papéis e valores. O governo, que saqueou e administrou mal os recursos da Previdência, faz pose de salvador e joga a culpa e a conta nas costas do funcionalismo, produzindo uma cortina de fumaça sobre sua verdadeira prioridade. Sacrificando o desenvolvimento do país e o bem-estar do povo, a meta desse governo é satisfazer a ganância da agiotagem internacional, na qual se incluem grandes agiotas brasileiros. 
PINHEIRO, C. L. A refutação no gênero artigo de opinião

Renato de Oliveira, 45, sociólogo, é presidente da Andes (Sindicato Nacional dos Docentes em Instituições de Ensino Superior).E-mail: andesnac@andes.com.br 